Materials Research Society Bulletin, vol. 28, 2003, 445-448

\title{
Toughening Epoxy Adhesives to Meet Today's Challenges
}

\author{
A.J. Kinloch \\ Department of Mechanical Engineering, Imperial College of Science, Technology and \\ Medicine, Exhibition Road, London SW7 2BX, UK
}

\begin{abstract}
There are many advantages that polymeric adhesives can offer compared to the more traditional methods of joining such as bolting, brazing, welding, mechanical fasteners, etc. and epoxy adhesives represent the most common type of structural adhesive. When polymerised, epoxy adhesives are amorphous and highly-crosslinked materials and this microstructure results in many useful properties for structural engineering applications, such as a high modulus and failure strength, low creep, and, by careful formulation, good performance at elevated temperatures. However, the structure of such thermosetting adhesives also generally leads to one highly undesirable property in that they are relatively brittle materials, with a poor resistance to crack initiation and growth. Nevertheless, the incorporation of a second phase of dispersed rubbery particles into the epoxy polymer can greatly increase their toughness without significantly impairing the other desirable engineering properties. Thus, such rubber-toughened epoxy adhesives can be used, for example, in applications where a very high impact resistance is required for the adhesivelybonded joint.
\end{abstract}

Key words: Adhesives; Epoxies; Fracture; Microstructure; Toughening.

\section{Introduction}

There are many advantages that polymeric adhesives can offer compared to the more traditional methods of joining such as bolting, brazing, welding, mechanical fasteners, etc. These include ${ }^{1,2}$ the ability to join dissimilar materials to give light-weight, but strong and stiff structures, such as honeycomb sandwich panels. Also, polymeric adhesives may be used to join thin-sheet material efficiently which, due to its low bearing strength, cannot be readily 
joined by other methods. Further, adhesive bonding frequently represents the most convenient and cost-effective joining technique and, indeed, the bonding operation can often be readily automated. For these reasons, adhesive bonding is widely used in many industries, for example in the automobile, truck, aerospace, railway and electronic industries. Epoxy adhesives represent the most common type of structural adhesive; the term structural meaning that the polymerised (i.e. cured or hardened) adhesive possesses a relatively high modulus and strength so that a load-bearing joint is formed.

\section{Background}

Epoxy adhesives essentially consist ${ }^{3}$ of an epoxy resin, often based upon the diglycidyl ether of bisphenol A (DGEBA), which harden, or cure, to give a thermosetting polymer by stepgrowth polymerisation or addition polymerisation.

In step-growth polymerisation a curing agent possessing active chemical groups, such as mercaptan, amine, amide or acid anhydride groups (which are hydrolysed by atmospheric moisture to acid groups), is added and reacts with the epoxy groups. This is illustrated by a typical reaction scheme shown in Figure 1. Note that the polymerisation does not involve a condensation reaction, so no volatiles are evolved. (The evolution of volatiles may lead to entrapped voids in the adhesive layer which would lower its stiffness and strength.) Such reactions may proceed either at room or elevated temperatures. The curing agent is added by the user in the case of a room-temperature hardening reaction, i.e. a two-part formulation, and the multifunctional hardeners that are commonly used are based upon, polyamineamides, aliphatic polyamines (e.g. diethylene triamine or $\mathrm{N}, \mathrm{N}$,-diethyl amino-propylamine) and polysulphides. When the hardening reaction proceeds only at elevated temperature, such as with the aromatic amine hardeners (e.g. diamino diphenyl sulphone) or dicyandiamide, the supplier often adds the hardener and the adhesive user purchases a one-part formulation. The one-part formulation may be supplied in the form of a paste or, when a high molecularweight epoxy and/or a high molecular-weight thermoplastic polymer is used in the formulation, in the form of a virtually tack-free film.

The addition polymerisation reaction involves polymerising through intermolecular reaction of the epoxy groups driven by an ionic reaction initiated by one of several types of catalyst which are present in the adhesive formulation, such as certain aromatic amines, $\mathrm{BF}_{3^{-}}$ 
amine complexes or imidazole complexes. The polymerisation reaction typically proceeds at an elevated temperature. Formulations employing the latent hardeners listed above are the basis for many of the current generation of one-part hot-cured formulations, in the form of pastes or films, especially those toughened by the inclusion of a rubber in the formulation, which significantly increase the toughness of the epoxy adhesive as discussed below.

\section{Increasing the Toughness}

\subsection{Introduction}

When polymerised, epoxy adhesives are amorphous and highly-crosslinked (i.e. thermosetting) materials. This microstructure results in many useful properties for structural engineering applications, such as a high modulus and failure strength, low creep, and good performance at elevated temperatures. However, the structure of such thermosetting polymers also leads to one highly undesirable property in that they are relatively brittle materials, with a poor resistance to crack initiation and growth. Nevertheless, the incorporation of a second phase of dispersed rubbery particles into the epoxy polymer can greatly increase their toughness, without significantly impairing the other desirable engineering properties ${ }^{4,5}$.

The actual microstructure of a cured rubber-toughened epoxy adhesive is obviously dependent upon the detailed polymerisation chemistry of the starting products and the heating cycle used to cure the adhesive. The microstructure, in turn, controls the mechanical behaviour of the cured adhesive and these properties, together with those of the materials to be bonded and the design of the adhesively-bonded joint, control the final properties of the bonded component. Thus, it is not surprising that predicting the behaviour of bonded joints from first principles as one travels up the length scale from molecular considerations to engineering structures is still a major challenge!

The optimum molecular structure of the rubber is determined by two main requirements: the rubber must be in the form of a well-dispersed separate phase in the cured adhesive and the rubber particles need to have good adhesion to the thermoset epoxy matrix in order to impart the best properties. To achieve these requirements the rubber is usually first pre-reacted with an epoxy resin, typically of the same chemical type as to be used in the formulation, to give an epoxy end-capped rubber adduct. This rubber adduct is then dissolved 
in the epoxy resin, but then phase separates in-situ as the adducted-rubber and the epoxy resin undergo polymerisation. Spherical particles of phase-separated, and now chain extended, rubber are therefore formed in a matrix of epoxy which continues to react until it is fully cured.

The problem of obtaining a rubber which is initially miscible with the epoxy resin, but which will itself polymerise and so phase separate during the cure process, is met by using a polar, low molecular-weight (liquid) rubber which possesses functional, reactive endgroups. A typical such rubber is a carboxyl-terminated butadiene-acrylonitrile (CTBN) which is represented schematically in Figure 2. In this structure, typically $m=10$ and the molecular weight is about $3500 \mathrm{~g} / \mathrm{mol}$. The values of $x$ and $y$ will determine the acrylonitrile content, and hence the polarity and compatibility of the rubber.

A typical microstructure of a rubber-toughened epoxy adhesive may be seen in Figure 3 which shows a transmission electron micrograph of a thin section. (The rubber employed was a CTBN copolymer and the section was exposed to osmium tetroxide prior to examination. The selective reactions of the reagent with the unsaturated butadiene groups increases the contrast between the rubbery particles and the epoxy matrix.) The data given in Table 1 are for a typical rubber-toughened epoxy which generally contains between 15 to $20 \%$ volume fraction of dispersed rubbery particles, which possess a diameter of between about 0.5 to $2 \mu \mathrm{m}$. (However, dependent on the epoxy being used and the level of toughness required, the volume fraction of rubber can be as low as 7.5 to 10\%.) Such data clearly reveal that this type of multiphase microstructure leads to major improvements in toughness, without significant losses in other important properties. For example, the fracture energy, $G_{c}$, has been increased by a factor of 10 to 15 whilst the modulus has been decreased by about only $15 \%$ and the upper glass transition temperature of the toughened polymer is unchanged.

\subsection{Toughening mechanisms}

\subsubsection{Introduction}

Many different mechanisms have been proposed to explain the greatly improved fracture toughness that may result when a polymeric epoxy adhesive possesses a multiphase microstructure of dispersed rubber particles. Much of the dispute has concerned whether the rubbery particles or the epoxy matrix absorbs most of the energy. However, work by Kinloch 
et al. $^{6,7}$ and independently by Yee and Pearson ${ }^{8}$ has clearly established that plastic deformation of the epoxy matrix is the main source of energy dissipation and increased toughness. Such enhanced plastic deformation arises from the interactions of the stress field ahead of a crack tip and the rubbery particles.

\subsubsection{Stress fields around the rubbery particles}

Several workers $^{9-12}$, using both analytical and more recently numerical methods, have considered the stresses around elastic spherical particles embedded in an isotropic matrix, where the matrix is subjected to applied tensile stresses. Such work reveals that for a rubbery particle, which typically possesses a considerably lower shear modulus than the matrix, there exists a tensile stress concentration in the matrix resulting from the presence of the particle, which occurs around the equator of the particle and has a value of about two. Furthermore, assuming that the particle is well bonded to the matrix, the local stress state at this point is one of triaxial tension. This tension arises essentially because of the volume constraint represented by the bulk modulus of the rubber particle, which is comparable with that of the matrix. The low shear modulus of the rubber particle relative to the thermoset matrix, in spite of its comparable bulk modulus, is a consequence of the Poisson's ratio of the rubber being approximately 0.5 ; whilst that of the matrix is about 0.35 . Thus, in contrast to a 'hole', which would produce a similar-size stress concentration, the rubbery particle can fully bear its share of the load across the crack front. This ability of the rubber particles to bear loads whilst functioning as stress concentrators can explain the observation that rubber particles are more effective for toughening the polymer, compared with 'holes'.

\subsubsection{Matrix plastic yielding and particle cavitation}

The stress field associated with the rubber particles leads to the initiation of two important deformation processes that can strongly interact.

One important process is the initiation and growth of multiple localised shear-yield deformations in the matrix. The stress concentrations around the rubber particles act as initiation sites for the plastic shear deformation. Because there are many particles, considerably more plastic deformation exists in the multiphase adhesive than in the unmodified material. However, the plastic deformation is localised through (a) the post-yield strain softening of the epoxy matrix, and (b) the fact that shear deformations initiate at one 
particle but terminate at another. The localised nature of the plastic shear bands, visible as furrows running at angles of approximately $45^{\circ}$ to the principal tensile stress, i.e. in the direction of maximum shear stress, is illustrated in Figure 4.

The other major deformation process is cavitation of the rubbery particle. In considering this phenomenon, it is necessary to recall that an overall triaxial stress state (plane strain) usually exists ahead of the crack tip and produces dilation. Combined with the stresses that are induced in the particle by cooling after cure, dilation causes failure and void formation in the rubbery particle. The formation of such a void in a rubbery particle is clearly shown in Figure 5. The importance of the formation of such voids in the rubbery particles ahead of the crack tip is not due to the energy that is associated with the formation of these voids. This is typically of little significance. Rather, is the fact that the formation of these voids enables further plastic deformation in the matrix to develop. This arises from two aspects. Firstly, the presence of the voids in the rubbery particles lowers the extent of stress triaxiality in the adjacent matrix, which lowers the stress required for shear yielding and so promotes more localised plastic shear deformations in the matrix of the type described above. Secondly, the formation of the voids in the rubbery particles enables plastic void, i.e. hole, growth in the epoxy matrix to occur ${ }^{13}$. Indeed, this is why the void in Figure 5 has not 'closed up', but it clearly visible as an 'open’ microcrack.

\subsection{Modifying the matrix ductility}

The toughening mechanisms outlined above highlight the role of the inherent ductility of the polymeric epoxy matrix in influencing the toughness of the multiphase adhesive. For example, a decrease in the stress needed for plastic shear-yielding should obviously assist in increasing the toughness, if all the other important microstructural features are unchanged. However, an increase in the inherent ductility of the matrix can often only be achieved at the expense of other important properties of the adhesive. Nevertheless, in recent years, increasing the inherent ductility of the epoxy polymer has been a major research focus in the effort to synthesise very tough epoxy adhesives.

One route to increasing the inherent ductility of the epoxy polymer is to relax the density of the crosslink network in the material and the effect of changing the molecular weight, $M_{c}$, between crosslinks has been studied by Pearson and $\mathrm{Yee}^{14}$ and Finch et al. ${ }^{15}$. The 
latter authors varied the molecular weight between crosslinks in the epoxy matrix of a model epoxy-CTBN system by changing the cure time and temperature. The microstructure of the dispersed rubbery particles in the rubber-toughened adhesives was found not to be significantly changed by the different curing conditions. Plane-strain compression tests on the unmodified polymers clearly revealed that, although the modulus and yield stress were not greatly affected, the maximum plastic strain capability of the matrix was dramatically increased as the value of $M_{c}$ was increased. The increased ductility of the matrix as the crosslink density was decreased, i.e. as the value of $M_{c}$ was increased, was indeed reflected in a higher value of the fracture energy, $G_{c}$, as may be seen from Table II.

A second route is form an epoxy matrix which has an enhanced molecular mobility via copolymerisation with a relatively flexible monomer or oligomer. Such a route may be achieved by designing the chemistry of the in-situ phase separation so that some of the added rubber remains in solution and reacts to chain-extend the epoxy matrix. However, whilst this may be effective in increasing the ductility of the epoxy matrix, it may lead to a loss of other properties which may be of importance, such as a decrease in the glass transition temperature, $T_{g}$, of the matrix. Thus, more recently, a very novel and successful route ${ }^{16}$ has been developed by the addition of a second rubber to the adhesive formulation, such as a reactive end-capped poly(ether urethane) which contains flexible poly(alkylene oxide) segments. The addition, followed by the in-situ phase separation, of the butadieneacrylonitrile and the poly(ether urethane) rubbers leads to a very complex microstructure for the cured adhesive. It appears that the epoxy matrix now possesses a co-continuous, interpenetrating network (i.e. two-phase IPN) structure at the nano-scale level, with a dispersed rubbery phase at the micro-scale level also present. This complex, multiphase microstructure leads to a highly ductile epoxy matrix which can respond very effectively to the toughening mechanisms initiated by the classical dispersed rubbery phase. Values of the fracture energy, $G_{c}$, of over $4000 \mathrm{~J} / \mathrm{m}^{2}$ have been reported ${ }^{17}$ for this exciting new class of structural adhesives.

\section{Concluding Remarks}

The development of multiphase thermosetting epoxy polymers for structural adhesive applications has led to major improvements in the toughness of such materials, and usually with no significant losses in other desirable properties. Two major challenges remain. The first is for modelling studies ${ }^{18}$ to progress to the stage when quantitative predictions of the 
toughness, and other engineering properties, can be accurately and reliably be made from a knowledge of (a) the microstructure of the multiphase material, and (b) the mechanical properties of the individual phases. The second challenge is for design engineers to use these adhesives to their full potential. This is certainly occurring at a rapid pace in the automobile industry, especially in the manufacture of vehicles based extensively upon the use of glassfibre reinforced plastics, aluminium alloys, engineering plastics and mixtures of these materials. For the joining of such materials, the traditional spot-welding techniques that have been used for steel can not be readily employed, and the new generation of very tough epoxy adhesives are now being used as the primary joining method in many very demanding, and critical, components and structures.

\section{Acknowledgements}

The author would wish to thank Mr. John Bishopp of Star Adhesion Ltd. (UK) for his very helpful comments on the paper. 


\section{References}

1. A.J. Kinloch, Adhesion and Adhesives: Science and Technology (Chapman and Hall, London, 1987).

2. A.J. Kinloch, Proc. Instn. Mech. Engrs. 211 Part G, (1997) p. 307.

3. I. Skeist, ed., Handbook of Adhesives (Van Nostrand Reinhold, New York, 1989).

4. $\quad$ E.H. Rowe, A.R. Siebert and R.S. Drake, Modern Plastics 49 Aug. (1970) p. 110.

5. $\quad$ R.S. Drake and A.R. Siebert, SAMPE Quart. 6 (4) (1975) p. 11.

6. A.J. Kinloch, S.J. Shaw, D.A. Tod and D.L. Hunston, Polymer 24 (1983) p. 1341.

7. $\quad$ A.J. Kinloch, S.J. Shaw and D.L. Hunston, Polymer 24 (1983) p. 1355.

8. $\quad$ A.F. Yee and R.A. Pearson, J. Materials Sci. 21 (1986) p. 2462.

9. J.N. Goodier, Trans. ASME 55 (1933) p. 39.

10. L.J. Broutman and G. Panizza, Int. J. Polymeric Materials 1 (1971) p. 95.

11. Y. Huang and A.J. Kinloch, J. Materials Sci. 27 (1992) p. 2753.

12. $\quad$ F.J. Guild and A.J. Kinloch, J. Materials Sci. 30 (1995) p. 1689.

13. Y. Huang and A.J. Kinloch, J. Materials Sci. Letters 11 (1992) p. 484.

14. R.A. Pearson and Y.F. Yee, Polymer Materials Sci. Preprints, Amer. Chemical Soc. 186 (1983) p. 316.

15. C.A. Finch, S. Hashemi and A.J. Kinloch Polymer Communications 28 (1987) p. 322.

16. R. Mulhaupt and U. Buchholz, in Toughened Plastics II, edited by C.K. Riew and A.J. Kinloch, eds., (Amer. Chemical Soc., Washington DC, 1996) p. 75.

17. B.R.K. Blackman, A.J. Kinloch, A.C. Taylor and Y. Wang, J. Materials Sci. 35 (2000) p. 1867.

18. A.J. Kinloch and F.J. Guild, in Toughened Plastics II, edited by C.K Riew and A.J. Kinloch, eds., (Amer. Chemical Soc., Washington DC, 1996) p. 1. 


\section{Table I}

Typical properties after curing of an unmodified and a rubber-toughened epoxy adhesive.

\begin{tabular}{|c|c|c|}
\hline Property & Unmodified epoxy & Rubber-toughened epoxy \\
\hline $\begin{array}{l}\text { Molecular weight, } M_{c} \text {, between } \\
\text { crosslinks in epoxy phase } \\
\qquad(\mathrm{g} / \mathrm{mol})\end{array}$ & $\approx 500$ & $\approx 500$ \\
\hline$T_{g}$ of epoxy phase $\left({ }^{\circ} \mathrm{C}\right)$ & 100 & 100 \\
\hline $\begin{array}{l}\text { Vol. fraction of dispersed } \\
\text { rubbery phase (\%) }\end{array}$ & - & 18 \\
\hline $\begin{array}{l}\text { Mean diameter of dispersed } \\
\text { rubbery phase }(\mu \mathrm{m})\end{array}$ & - & 1.6 \\
\hline$T_{g}$ of rubbery phase $\left({ }^{\circ} \mathrm{C}\right)$ & - & -55 \\
\hline Tensile fracture stress (MPa) & 63 & 58 \\
\hline Tensile fracture strain (\%) & 5 & 9 \\
\hline Young's modulus (GPa) & 3.3 & 2.8 \\
\hline Fracture energy, $G_{c},\left(\mathrm{~J} / \mathrm{m}^{2}\right)$ & 200 & 2000 to 3000 \\
\hline $\begin{array}{l}\text { Izod impact strength }(\mathrm{J} / \mathrm{m} \text { of } \\
\text { notch) }\end{array}$ & 0.7 & 3 to 5 \\
\hline
\end{tabular}

Note: $T_{g}$ is the glass transition temperature of the polymer. 


\section{Table II}

Effect of varying the molecular weight, $M_{c}$, between crosslinks on the fracture energy, $G_{c}$, of a rubber-toughened epoxy adhesive.

\begin{tabular}{|c|c|c|c|}
\hline Cure conditions & $M_{c}(\mathrm{~g} / \mathrm{mol})$ & $T_{g}$ (matrix) $\left({ }^{\circ} \mathrm{C}\right)$ & $G_{c}\left(\mathrm{~J} / \mathrm{m}^{2}\right)$ \\
\hline $16 \mathrm{~h}$ at $120^{\circ} \mathrm{C}$ & 610 & 100 & 2230 \\
\hline 6 h at $160^{\circ} \mathrm{C}$ & 4640 & 89 & 5900 \\
\hline
\end{tabular}




\section{List of Figure Captions}

Figure 1 Typical epoxy resin and hardening reactions using a primary diamine hardener. (a) A bisphenol A-epichlorohydrin based epoxy resin. The most important type is when $n=0$ and the liquid epoxy resin is essentially (b) a simple diglycidyl ether of bisphenol A (DGEBA). (c) A primary amine hardener. (d) A crosslinked (i.e. thermoset) polymeric epoxy adhesive.

Figure 2 The chemical structure of a typical (liquid) rubber used for toughening the epoxy adhesive. The above is a carboxyl-terminated butadiene-acrylonitrile (CTBN), generally $m=10$ and the molecular weight is about $3500 \mathrm{~g} / \mathrm{mol}$.

Figure 3 Transmission electron micrograph of an osmium-tetroxide stained section of a rubber-modified epoxy adhesive. It shows the typical microstructure of dispersed rubbery particles in the matrix of the epoxy polymer. (The wavy lines are artefacts due to the cutting of a very thin section of material.)

Figure 4 Scanning electron micrograph of surface, normal to the crack plane, of a rubber-toughened epoxy adhesive. The furrows between the rubber particles, at approximately $45^{\circ}$ to the maximum principal tensile stress, are caused by the plastic shear deformation bands that occur at constant volume.

Figure 5 Scanning electron micrograph of the fracture surface of a rubber-toughened epoxy adhesive showing the cavitated rubbery particles. 
Figure 1

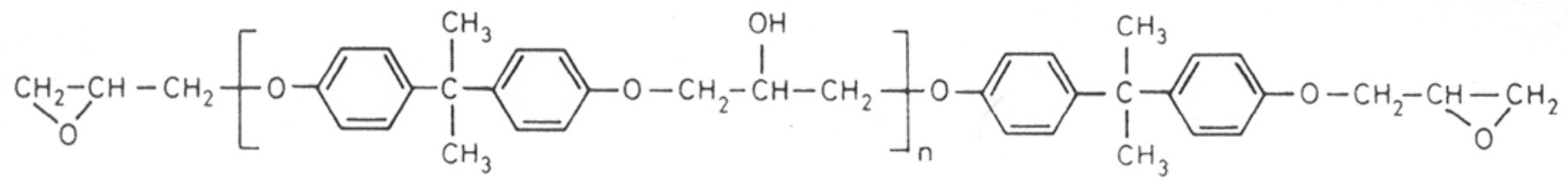

(a)
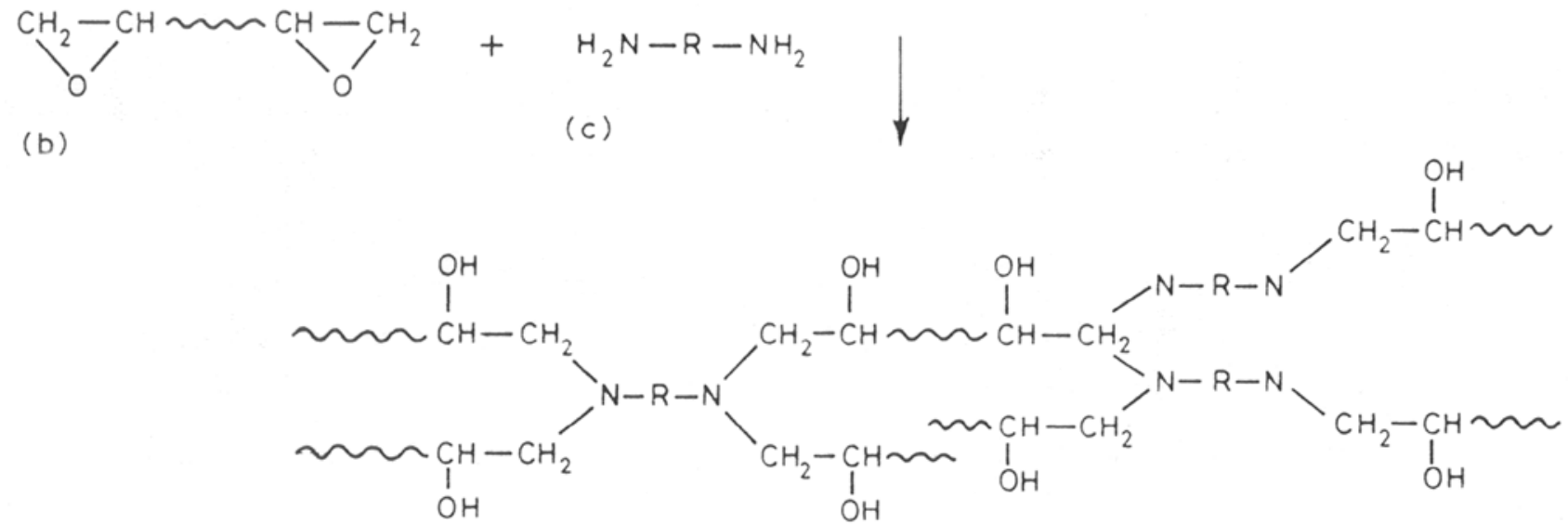

(d) 
Figure 2

HOOC $-\left(\mathrm{CH}_{2}-\mathrm{CH}=\mathrm{CH}-\mathrm{CH}_{2}\right)_{x}-\left(\mathrm{CH}_{2}-\underset{\mathrm{CN}}{\mathrm{CH})_{y}}\right]_{m} \mathrm{COOH}$ 
Figure 3

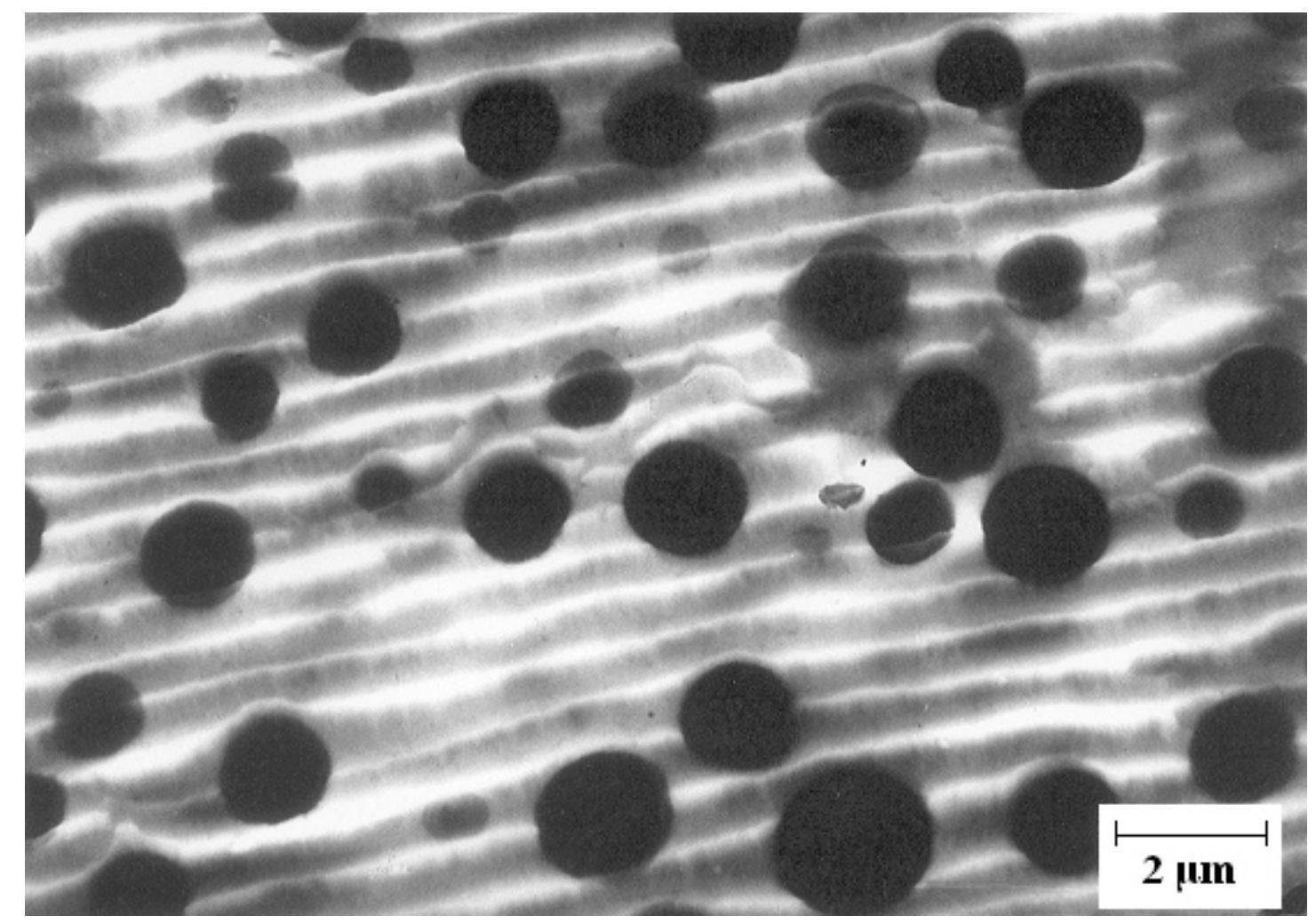


Figure 4

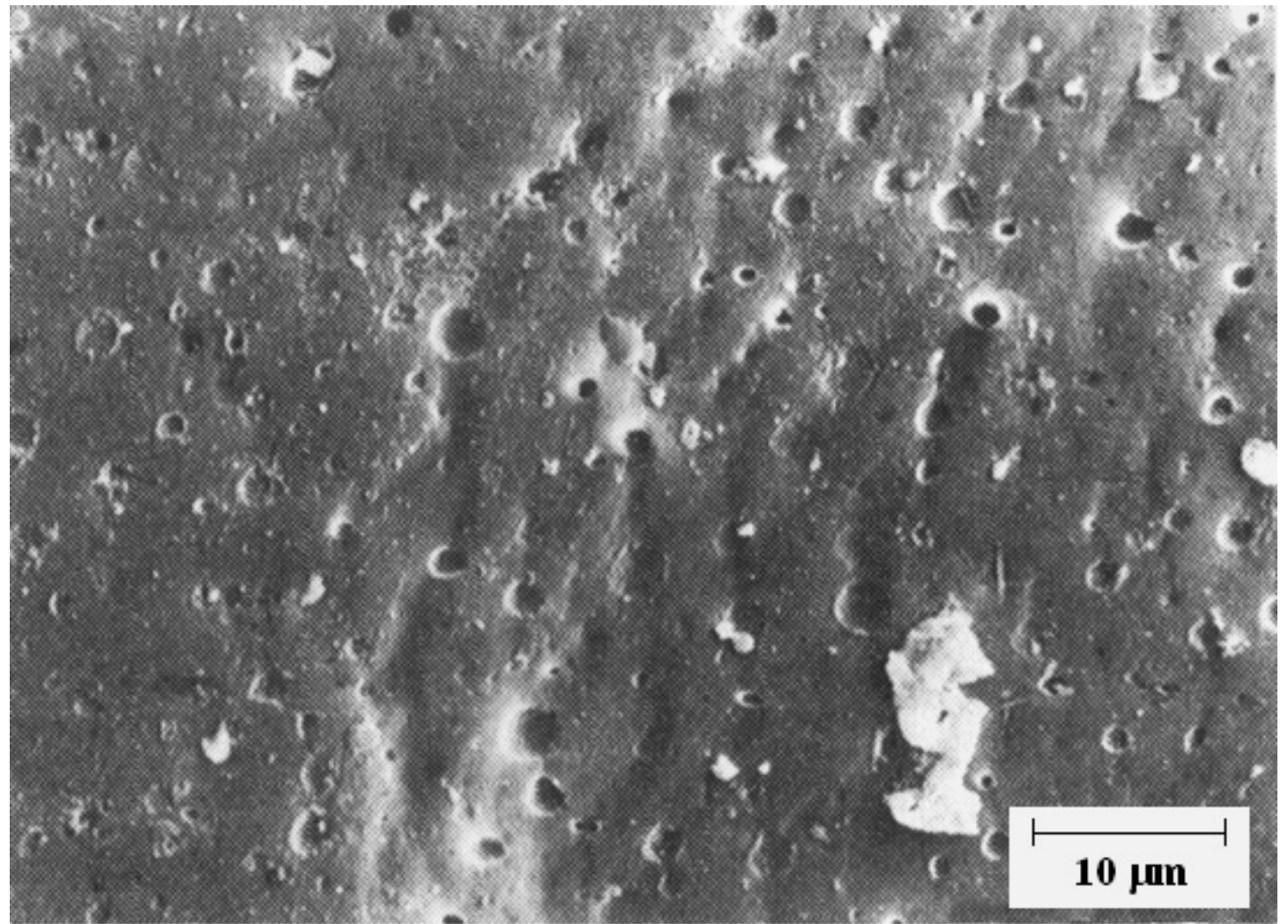


Figure 5

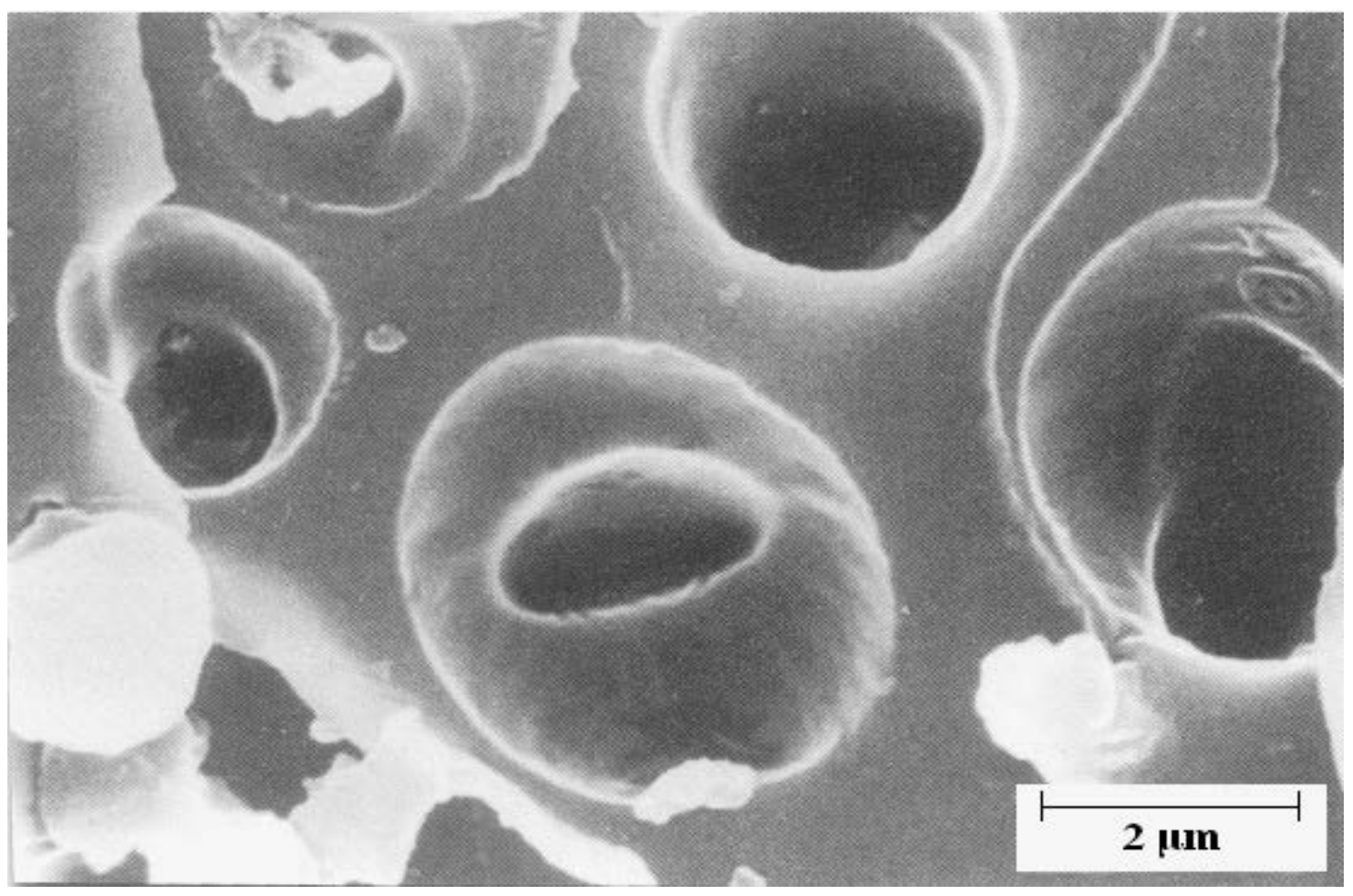

